\title{
DESIGN AND DEVELOPMENT OF TOPICAL HYDROGEL FORMULATION OF IRBISARTAN
}

\author{
ZEESHAN SHAIKH \\ Swami Vivekanand College of Pharmacy Indore, Madhya Pradesh, India \\ Email: jshaikh660@gmail.com
}

Received: 16 Apr 2019, Revised and Accepted: 13 Jun 2019

\begin{abstract}
Objective: Irbesartan is an antihypertensive with limited bioavailability. The objective of the study was to develop controlled release matrix tablets of irbisartan drug.

Methods: Tablets were prepared by wet granulation process. Result: In vitro drug release study revealed that HPMC causes initial burst release of drug hence combining HPMC sustained the action for $8 \mathrm{~h}(95.92 \pm 0.57 \%$ release). Fitting the in vitro drug release data to Korsmeyer equation indicated that diffusion along with erosion could be the mechanism for drug release. Compared to conventional tablets, the release of model drug from these HPMC matrix tablets was prolonged, leading to achieve an effective therapy with a low dosage of the drug, to reduce the frequency of medication. The pharmacological and clinical properties of irbesartan, a noncompetitive angiotensin II receptor type 1 antagonist, successfully used for more than a decade in the treatment of essential hypertension.
\end{abstract}

Results: Compatibility Studies In order to investigate the possible interactions between irbesartan and distinct polymers and/or diluents, FT-IR and DSC studies were carried out. FT-IR results proved that the drug was found to be compatible with excipients as wave numbers are almost similar for pure drug and also drug excipients mixture. In picture 1 and 2. DSC studies indicate that chosen excipients for the formulation were found to be compatible with the active ingredient as the melting endothermic peaks are in the range of $250-320^{\circ} \mathrm{C}$ which is same as the melting point of irbisartan.

Conclusion: Irbesartan exerts its antihypertensive effect through an inhibitory effect on the pressure response to angiotensin II. Irbesartan 150$300 \mathrm{mg}$ once daily confers a lasting effect over $24 \mathrm{~h}$, and its antihypertensive efficacy is further enhanced by the coadministration of hydrochlorothiazide.

Keywords: Irbisartan, Hydrogel, HPMC, Matrix tablet, Simplex lattice design and Oral controlled drug delivery system

(C) 2019 The Authors. Published by Innovare Academic Sciences Pvt Ltd. This is an open access article under the CC BY license (http://creativecommons.org/licenses/by/4.0/) DOI: http://dx.doi.org/10.22159/ijcpr.2019v11i4.34924

\section{INTRODUCTION}

Hydrogel the most promising alternative drug delivery systems for improving the bioavailability and therapeutic availability of the drugs. High patient compliance and flexibility in designing dosage forms attracted the oral drug delivery systems to be the most convenient mode of drug administration when compared to other dosage forms. Of these, matrix systems have gained widespread importance in controlled drug delivery due to cost-effective manufacturing technology [1,2].

Matrix drug delivery systems are of two types: diffusion/swellable systems and dissolution systems. In diffusion systems, drug release is mainly governed by the hydration of matrices followed by diffusion of the drug molecules from the hydrated layer to the surrounding bulk solution, and sometimes, partially by erosion/dissolution. Cellulose ethers are the best examples of such systems. With dissolution systems, drug release is mainly due to dissolution/erosion of the matrix and hence, the achievement of constant drug delivery rate is easier by this systems1. Hydrophilic matrix tablets are among the most popular delivery systems for oral controlled release dosage forms. These hydrophilic matrices are widely accepted because of their biopharmaceutical and pharmacokinetics advantages over conventional dosage forms. This is largely because they offer exact modulation of drug release as a result of hydration of the constituent polymer(s), flexibility to obtain desired drug release profiles, cost-effectiveness, patient compliance, providing a constant, prolonged, and uniform therapeutic effect and broad Food and Drug Administration (FDA) acceptability. The swelling rate and erosion of HPMC-based matrix tablet in aqueous media are very crucial in terms of achieving the desired release profiles and are affected by parameters such as the physicochemical properties of the polymer and the drug, processing conditions, the testing medium used and the formulation composition.
Hypertension is the leading cause of mortality in the world after malnutrition. Irbisartan is a competitive antagonist of AngiotensionII (AT II), devoid of partial agonistic activity and 10,000 more selective for AT1 and AT2 receptor, does not block any other receptor or iron channel. It blocks all over the action of AT II, the main adverse effect is dose-related hypotension. Irbisartan is a potent, highly specific angiotensin II type 1 (AT1) receptor antagonist with antihypertensive activity. It is readily absorbed from the gastrointestinal tract with oral bioavailability of about $33 \%$ and a plasma elimination half-life ranging from 1.5 to $2.5 \mathrm{~h}$. Administration of LP in a controlled release dosage form with an extended release over $8 \mathrm{~h}$, would be more desirable as these characteristics would allow a rapid onset followed by protracted anti-hypertensive effects by maintaining the plasma concentrations of the drug well above the therapeutic concentration. The current study aimed at developing and optimizing an oral sustained release dosage form of LP using computer-aided optimization technique i.e. simplex lattice statistical design with constraints on cumulative percentage release of drug after $8 \mathrm{~h}(95.92 \pm 0.57 \%)$. The Independent variables for the present study were: the amount of HPMC $15 \mathrm{cps}(\mathrm{C})$, amount of Ethylcellulose (D). The dependent variables studied were the 1 hour drug release(R1), 4 $\mathrm{hr}$ drug release(R2), $8 \mathrm{hr}$ drug release(R3) and T50\%-Time required for $50 \%$ drug release(R4)2 [1-6]

\section{MATERIALS AND METHODS}

Irbisartan was provided sun pharma dewas (m. p.). HPMC 15cps and Ethylcellulose, pvp, mg. stearate, aerosil and lactose.

\section{Methods}

\section{Preparation of controlled release matrix tablets}

The tablets were prepared by wet granulation method. The different stages involved in the process are: All the raw materials were passed 
through sieve no. 60 and weighed accurately as per the formulae irbisartan, Polymers (HPMC 15cps and Ethylcellulose), PVP, Aerosil and Lactose were mixed thoroughly by triturating in mortar and pestle to get a uniform mix. The thoroughly mixed powder was kneaded for $10 \mathrm{~min}$ with Isopropyl alcohol solution till it forms dough mass. This mass was passed through sieve no. 20 to form granules. The granules were spread on the tray and kept for drying at $50{ }^{\circ} \mathrm{C}$ for $30 \mathrm{~min}$ using hot air oven. The dried granules were passed through the sieve no. 40 to get fines and uniform sized granules and blended with magnesium Stearate. The precompression parameters were studied. The controlled release matrix tablets were prepared using $8 \mathrm{~mm}$ biconcave round punch in 10 station rotary compression machine. The working formula is given in table 1 and 2.

\section{Evaluation parameters}

Evaluated for both precompression and post-compression parameters, they includes-Bulk density, Tapped density, Carr's Index, Angle of Repose, Hardness, Friability, Weight variation test, Thickness3 [4].

\section{Drug content}

Five tablets were powdered in a mortar. Weighed accurately the quantity equivalent to $50 \mathrm{mg}$ of Losartan potassium and transferred to a $100 \mathrm{ml}$ volumetric flask containing few $\mathrm{ml}$ of distilled water and mixed well, made up the volume up to $100 \mathrm{ml}$ with distilled water. Pipette out $10 \mathrm{ml}$ from the stock solution into another $100 \mathrm{ml}$ volumetric flask and made up the volume with distilled water. From the above solution withdrew the aliquots of $2 \mathrm{ml}, 2.4 \mathrm{ml}$ and $3.2 \mathrm{ml}$ (as per Beer's range 2-20 $\mu \mathrm{g} / \mathrm{ml}$ ) and the volume was made up to 10 $\mathrm{ml}$ with distilled water. The absorbance was measured at $262 \mathrm{~nm}$ using distilled water as blank.

\section{In vitro release studies}

The in vitro dissolution profile of the designed formulations of controlled release tablets was carried out using USP type II apparatus under conditions specified (temp $37 \pm 0.50 \mathrm{C}, 75 \mathrm{rpm}$ ). Tablets were subjected to dissolution for the first two hrs in $0.1 \mathrm{~N}$ $\mathrm{HCl}$ next six hrs till the end of dissolution studies. From the dissolution medium withdrawn and replaced $1 \mathrm{ml}$ for every $5 \mathrm{~min}$, for the solution withdrawn volume was made up to $10 \mathrm{ml}$ with distilled water and absorbance was measured at $262 \mathrm{~nm}$ using distilled water as blank. Dissolution profiles of the formulations were analyzed by plotting drug release versus time plot.

\section{RESULTS}

Compatibility Studies In order to investigate the possible interactions between irbisartan and distinct polymers and/or diluents, FT-IR and DSC studies were carried out. FT-IR results proved that the drug was found to be compatible with excipients as wave numbers are almost similar for pure drug and also drug excipients mixture. In picture 1 and 2. DSC studies indicate that chosen excipients for the formulation were found to be compatible with the active ingredient as the melting endothermic peaks are in the range of $250-320{ }^{\circ} \mathrm{C}$ which is same as the melting point of irbisartan.

\section{Evaluation of pre-compression parameters}

Based on the results of pre-compression tests, all the formulations showed an angle of repose ranging from $22.210 \pm 0.84$ to $27.50 \pm 0.94$ indicating a good flow property (table 2) and Carr's index ranging from $10.53 \pm 0.01$ to $23.22 \pm 0.22 \%$, indicating compressibility of the granules is fairly passable (table 2 ).

\section{Evaluation of post-compression parameters}

The tablets of different formulations were subjected to various evaluation tests, such as thickness, uniformity of weight, hardness, friability, and drug content and the result are shown in table 3. All the formulations showed uniform thickness. The thickness and hardness of the tablets were in the range of $4.19 \pm 0.01$ to $4.22 \pm 0.01$ $\mathrm{mm}$ and $9.55 \pm 0.40$ to $9.33 \pm 0.40 \mathrm{~kg} / \mathrm{cm} 2$ respectively. The percentage friability was found to be less than $1 \%$ indicating that the friability is within the prescribed limits. In weight variation test, the average percentage deviation of all tablet formulations was found to be within the limit, and hence they met the test as per official requirements and were found to contain $40.32 \pm 0.66$ to $54.17 \pm 0.47$ $\mathrm{mg}$ of the labeled amount of irbisartan indicating uniformity of drug content.

In vitro release Tablets subjected for dissolution studies shown drug release at $1 \mathrm{hr}$ was ranging between $17.58 \pm 2.97$ to $32.52 \pm 0.30 \%$. As the dissolution studies continued, the release from each dosage form showed an incremental release in sustained manner for a long time suggesting a Sustained-release pattern (fig. 1,2 and 3). The release of the drug at $8 \mathrm{hr}$ varied from $72.93 \pm 0.58$ to $100.71 \pm 3.56 \%$ indicating that the overall drug release from the dosage form depends upon the composition of tablet matrix which varies from one formula to another. From this study, it may be concluded, that the independent variables included in the study were found to show significant variation for the response variables.

\section{Optimization}

The optimized formulation (table 4) was prepared and evaluated for various precompression, post-compression parameters and various responses. Pre-compression parameters of optimized formulation having the Angle of repose in the range of $26.21^{\circ} \pm 1.08$ indicating a good flow property and Carr's Index in the range of $14.90 \pm 0.09 \%$ indicating compressibility of the granules is passable (table 5). Postcompression parameters of optimized formulation having the weight variation in the range of $200.8 \pm 1.83 \mathrm{mg}$, thickness in the range of $4.20 \pm 0.01 \mathrm{~mm}$, hardness in the range of $9.33 \pm 0.40 \mathrm{~kg} / \mathrm{cm} 2$ and friability $0.07 \%$, which shows all the post-compression parameters, met the test as per official requirements (table 6). In case of in-vitro dissolution profile, the optimized formulation showing drug release at $1 \mathrm{~h}$ was $18.87 \pm 0.72$, at $4 \mathrm{~h}$ was $55.50 \pm 0.0$ and release of the drug at 8 $\mathrm{hr}$ was $95.92 \pm 0.57$ indicating that the overall drug release from the dosage form follows zero order drug release profile (fig. 3).

\section{Stability studies}

The optimized formulation was found to be stable in terms of physical appearance, hardness and drug content after 2 mo when it is stored under accelerated stability conditions as per ICH guidelines.

Table 1: Working Formula: F1-F5 by wet granulation method

\begin{tabular}{|c|c|c|c|c|c|c|}
\hline S. No. & Formulation code & F1 & F2 & F3 & F4 & F5 \\
\hline 1. & Drug & 50 & 50 & 50 & 50 & 50 \\
\hline 2. & HPMC 15caps & 50 & 100 & 0 & 40 & 60 \\
\hline 3. & Ethyle cellulose & 50 & 0 & 100 & 60 & 40 \\
\hline 4. & PVP & 5 & 5 & 5 & 5 & 5 \\
\hline 5. & Mg. stearate & 4 & 4 & 4 & 4 & 4 \\
\hline 6. & Aerosil & 1 & 1 & 1 & 1 & 1 \\
\hline 7. & Lactose & 40 & 40 & 40 & 40 & 40 \\
\hline 8. & Total wt. & 200 & 200 & 200 & 200 & 200 \\
\hline
\end{tabular}

The above quantites are expressed in terms of mg per tablet 
Table 2: Pre-compression parameters of matrix tablets

\begin{tabular}{lllll}
\hline S. No. & Formula & Bulk density & Tapped density & Carr's index \\
\hline 1. & F1 & $0.46 \pm 0.00$ & $0.53 \pm 0.00$ & $14.16 \pm 0.03$ \\
2. & F2 & $0.41 \pm 0.00$ & $0.49 \pm 0.00$ & $18.54 \pm 0.03$ \\
3. & F3 & $0.47 \pm 0.00$ & $0.52 \pm 0.00$ & $10.54 \pm 0.01$ \\
4. & F4 & $0.47 \pm 0.00$ & $0.56 \pm 0.00$ & $10.54 \pm 0.01$ \\
5. & F5 & $0.38 \pm 0.00$ & $0.56 \pm 0.00$ & $14.85 \pm 0.04$ \\
\hline
\end{tabular}

Table 3: Post-compression parameters of matrix tablets

\begin{tabular}{llllll}
\hline S. No. & Formula & Weight variation & Drug content & Hardness (kg/cm2) & Thickness (mm) \\
\hline 1. & F1 & $200 \pm 1.02$ & 40.32 & $9.55 \pm 0.40$ & $4.19 \pm 0.02$ \\
2. & F2 & $199 \pm 1.32$ & 38.52 & $10.11 \pm 0.32$ & $4.19 \pm 0.01$ \\
3. & F3 & $201 \pm 1.22$ & 36.82 & $8.5 \pm 0.52$ & $4.19 \pm 0.01$ \\
4. & F4 & $200 \pm 0.01$ & 41.32 & $9.33 \pm 0.22$ & $4.19 \pm 0.01$ \\
5. & F5 & $201 \pm 1.2$ & 54.17 & $8.66 \pm 0.36$ & $0.15 \pm 0.01$ \\
\hline
\end{tabular}

Table 4: Optimized formula for matrix tablets

\begin{tabular}{lll}
\hline S. No. & Ingredients & Quantity per tab \\
\hline 1. & Irbisartan & 50 \\
2. & HPMC 15caps & 60 \\
3. & Ethyle cellulose & 40 \\
4. & PVP & 5 \\
5. & Mg. stearate & 1 \\
6. & Aerosil & 4 \\
7. & Lactose & 40 \\
\hline
\end{tabular}

Table 5: Pre-compression parameters of optimized matrix tablets

\begin{tabular}{lll}
\hline S. No. & Parameters & Result \\
\hline 1. & Bulk density $(\mathrm{g} / \mathrm{cc})$ & $0.43 \pm 0.00$ \\
2. & Tapped density $(\mathrm{g} / \mathrm{cc})$ & $0.50 \pm 0.00$ \\
3. & Carr's Index $(\%)$ & $14.90 \pm 0.09$ \\
4. & Angle of repose $\left({ }^{\circ}\right)$ & $26.21 \pm 1.08$ \\
\hline
\end{tabular}

Table 6: Post-compression parameters of Optimized matrix tablets

\begin{tabular}{lll}
\hline S. No. & Parameters & Result \\
\hline 1. & Weight variation(mg) & $200.8 \pm 1.83$ \\
2. & Drug content(mg & $52.68 \pm 0.72$ \\
3. & Hardness(kg/cm2) & $9.33 \pm 0.40$ \\
4. & Thickness(mm) & $4.20 \pm 0.01$ \\
5. & \% Friability & $0.07 \pm 0.00$ \\
\hline
\end{tabular}

Dissolution profile of formulation F1-F5

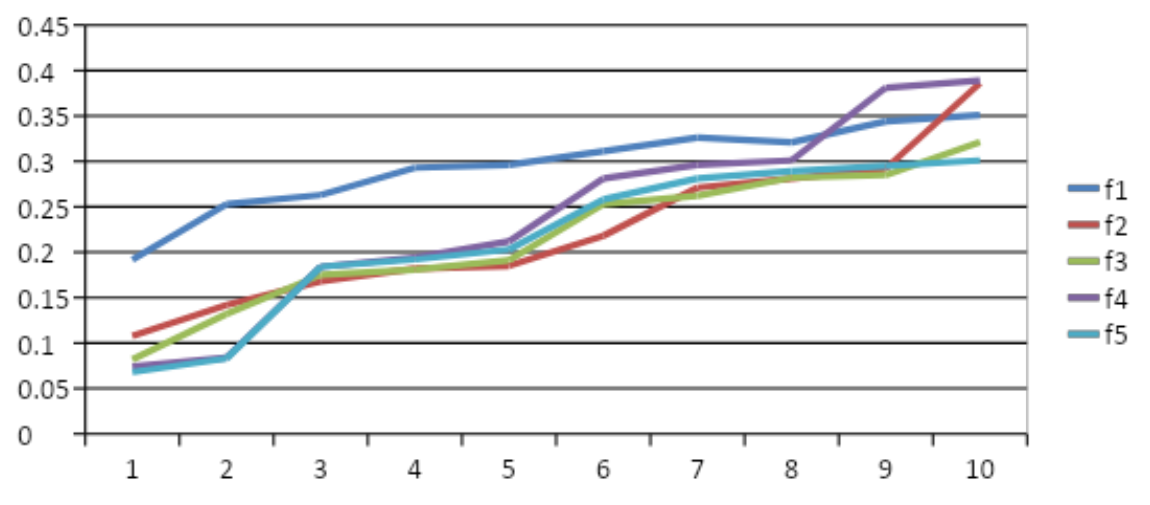

Fig. 1: Dissolution profile for matrix tablets of formulations F1-F5 


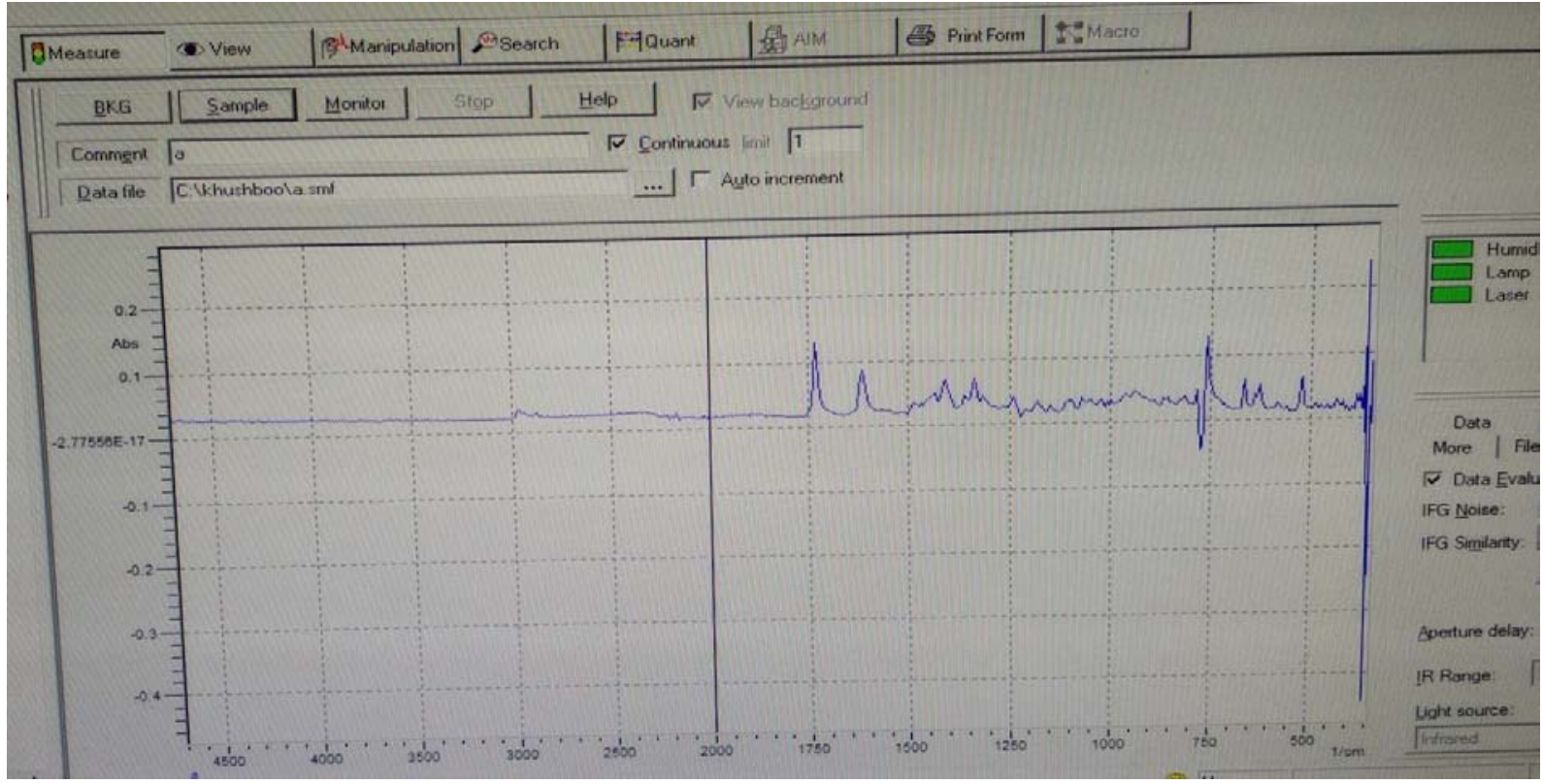

Picture 1: Ft-Ir profile of irbisartan

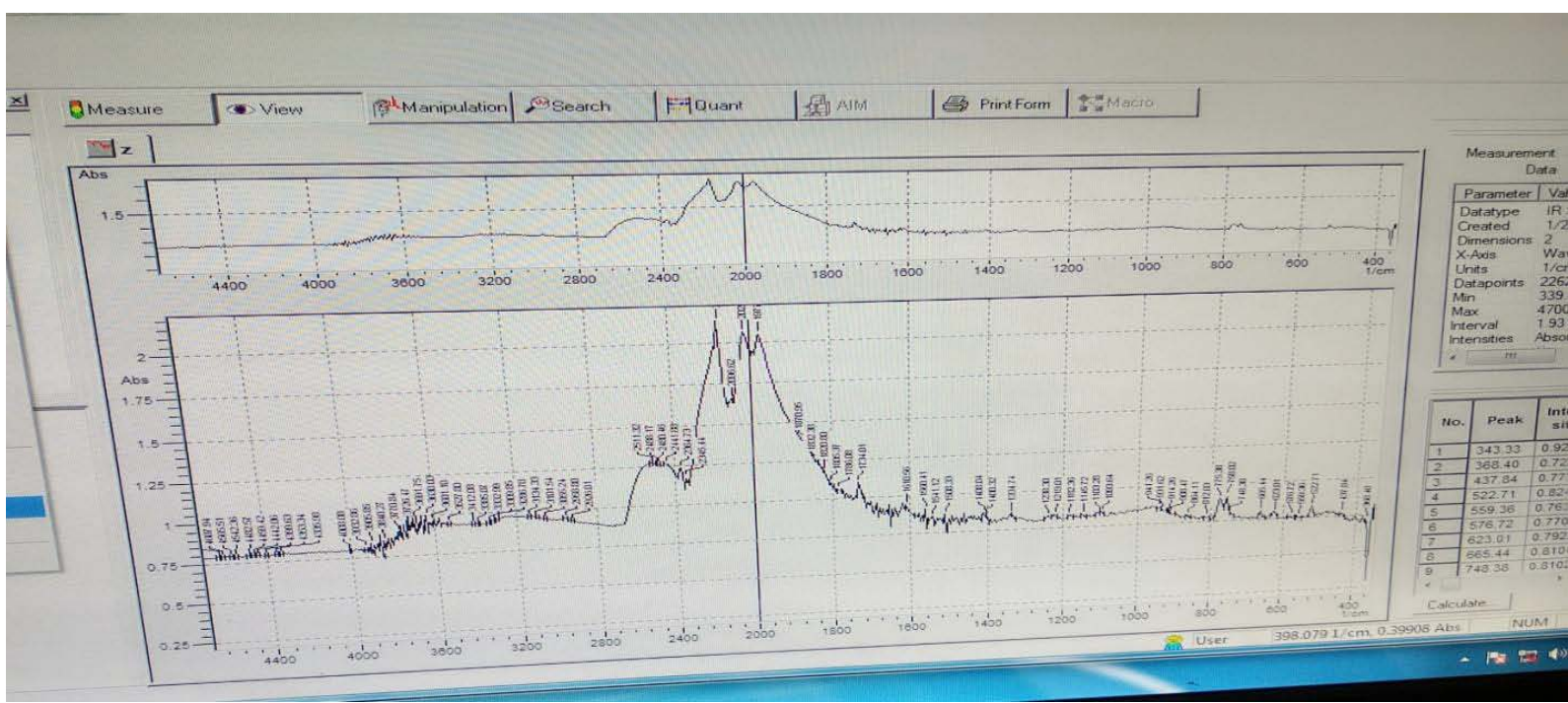

Picture 2: Ft-Ir profile of irbisartan

\section{CONCLUSION}

The application of experimental design assisted in successfully developing an oral controlled release dosage form for irbesartan. Simplex Lattice design was used to study the effect of different formulation variables on the release profile to select optimized formulation by using a numerical optimization technique. Finally, it can be concluded that the preparation of a controlled release drug delivery system is simplified by the use of simple, cost-effective, naturally occurring excipients. This method may be promising in the field of preparation of delayed release dosage form as the drug release profile is complying with USP tolerance.

\section{ACKNOWLEDGMENT}

We would like to thanks swami Vivekanand college of pharmacy Indore, Madhya Pradesh, India for continuous support and encouragement throughout this work.

\section{AUTHOR CONTRIBUTION}

All the work have been carried out by me

\section{CONFLICT OF INTERESTS}

Declare none

\section{REFERENCES}

1. Arumugam K, Chamallamudi MR, Mallayasami SR, Ganesan S, Shavi $\mathrm{GV}$, Averineni R, et al. Gender differences in the pharmacokinetics of rivastigmine in rats. Arzneimittel Forsch 2009;59:493-7.

2. Toti US, Aminabhavi TM. Modified guar gum matrix tablet for controlled release of diltiazem hydrochloride. J Controlled Release 2004;95:567-77.

3. Shruti Chopra GV Patil, Motwani SK. Release modulating hydrophilic matrix systems of losartan potassium: optimization of formulation using statistical experimental design. Eur J Pharm Biopharm 2007;66:73-82.

4. Lachman L, Lieberman HA, Kanig editors JL. The theory and practice of industrial pharmacy. 1st edition. Varghee publishing house, Bombay; 1991. p. 293-430.

5. Bravo SA, Lamas MC, Salomon CJ. In vitro studies of diclofenac sodium controlled release from bio-polymeric hydrophilic matrices. J Pharm Pharm Sci 2002;5:213-9. 
6. Al-Saidan SM, Krishnaiah YS, Patro SS, Satyanaryana V. In vitro and in vivo evaluation of guar matrix tablets for oral controlled release of water-soluble Diltiazem HCl. AAPS PharmSciTech 2005;6:14-21.

7. Khullar P, Khar RK, Agarwal SP. Evaluation of hydrogel-based controlled release niacin tablets. Drug Dev Ind Pharm 1998;24:479-83.

8. Rokade AP, Kulkarni PV, Mallikarjuna NN, Aminabhavi TM. Preparation and characterization of novel semiinterpenetrating polymer network hydrogel microspheres of chitosan and hydroxyl propyl cellulose for controlled release of chlorothiazide. J Microencapsulation 2009;26:27-36.

9. Elkheshen S, Yassin AE, Alkhaled F. Per-oral extended release bioadhesive tablet formulation of Verapamil Hcl hydrogel tablets. Boll Chim Farm 2003;142:226-31.

10. Atul Kuksal, Tiwary AK, Jain NK, Jain S. Formulation and in vitro, in vivo evaluation of extended release matrix tablets of
Zidovudine: influence of the combination of hydrophilic and hydrophobic matrix formers. AAPS PharmSciTech 2006;7:1-8.

11. Chen Chih Ming, Chiao, Charles SL. Controlled release hydrogel formulation, U. S. Patent US 5419917; 1995.

12. Gupta NV, Satish CS, Shivakumar HG. Preparation and characterization of gelatin-poly (methacrylic acid) interpenetrating polymer network hydrogels as a $\mathrm{pH}$-sensitive delivery system for Glipizide. Indian J Pharm Sci 2007;69:64-8.

13. Changez M, Burugapalli K, Koul V, Choudhary V. The effect of the composition of poly (acrylic acid)-gelatin hydrogel on gentamycin sulphate release: in vitro. Bio-materials 2003;24:527-36.

14. Hemant YKS, Satish CS, Shivakumar HG. Preparation and evaluation of chitosan-poly (acrylic acid) hydrogels as stomach specific delivery for amoxicillin and metronidazole. Ind J Pharm Sci 2007;69:91-5. 